\title{
ENQUANTO ARTISTA: RUMOS DE UMA POÉTICA
}

\author{
Como artista: rumbos de una poética
}

As an artist: paths of a poetic

Reinilda de Fátima Berguenmayer Minuzzi ${ }^{1}$

\begin{abstract}
Resumo
Artista-professor ou professor-artista e/ou artista-pesquisador ou pesquisador-artista: vários ângulos de uma mesma questão, equacionada diferentemente na prática pessoal e de muitos docentes que atuam no campo da Arte. No caso particular, vão-se mais de duas décadas em produções artísticas híbridas, mais recentemente fundadas em Arte e Tecnologia, revelando peculiaridades do percurso que teve base gráfica em experimentações com o desenho, a colagem, o objeto-arte, os materiais têxteis, a impressão e a estampa. Ora plana, ora tridimensional, ora imaterial, a produção artística pessoal, nesta trajetória, parte de algo físico, tangível e agrega a isso, em seu caminho, a imagem digital fixa ou não. Neste sentido, o artigo apresenta considerações sobre passos e projetos da prática artística, condicionados por contextos específicos e realizados em torno do âmbito institucional, ou seja, como professora-artista.
\end{abstract}

Palavras-chave: Poéticas Visuais; Processos Híbridos; Produção artística pessoal

\section{Resumen}

Artista-profesor o profesor-artista o artista-investigador o investigador-artista: varios ángulos de una misma cuestión, ecuacionada diferentemente en la práctica personal y de muchos docentes que actúan en el campo del arte. En el caso particular, se van más de dos décadas en producciones artísticas híbridas, más recientemente fundadas en Arte y Tecnología, revelando peculiaridades del recorrido que tuvo base gráfica en experimentaciones con el diseño, el collage, el objeto-arte, los materiales textiles, la impresión y la estampa. En el caso de que se trate de una obra de arte personal, en esta trayectoria, parte de algo físico, tangible y agrega a ello, en su camino, la imagen digital fija o no. En este sentido, el artículo presenta consideraciones sobre pasos y proyectos de la práctica artística, condicionados por contextos específicos y realizados en torno al ámbito institucional, o sea, como profesora-artista.

Palabras clave: Poéticas visuales; Procesos Híbridos; Producción artística personal

\begin{abstract}
Artist-teacher or artist-teacher and/or artist-researcher or researcher-artist: several angles of the same question, equated differently in personal practice and for many teachers who work in the field of art. In this particular case, more than two decades have been devoted to hybrid artistic productions, more recently founded in Art and Technology, revealing the peculiarities of the route that had a graphic basis in experiments with drawing, collage, object-art, textile materials, the printing and stamping processes. Sometimes flat, sometimes three-dimensional, sometimes immaterial, the personal artistic production, in this trajectory, part of something physical, tangible and adds to it, in its path, the digital image fixed or not. In this sense, the article presents considerations about steps and projects of the artistic practice, conditioned by specific contexts and carried out around the institutional scope, that is, as teacher-artist.
\end{abstract}

Keywords: Visual Poetics; Hybrid Processes; Personal artistic production

1 Departamento de Artes Visuais, Universidade Federal de Santa Maria, Santa Maria, Rio Grande do Sul, Brasil, e-mail: reibmin@yahoo.com.br 


\section{Domínios do subjetivo: afluências criativas no fazer artístico}

De uma demanda individual internalizada como única opção de formação acadêmica e, posteriormente, de atuação profissional, o encontro com a área de Artes Visuais² foi simples e decisivo, chegando ao ponto onde "era isso" ou "era isso", sem qualquer dúvida. A perspectiva de lidar com aspectos da criatividade e do imaginário, aplicados às artes gráficas, foi o desejo propulsor de tal trajetória. A realidade encontrada nos bancos universitários foi a de uma graduação voltada ao design de interiores e à arte decorativa, tendo em vista que artes gráficas não constituía mais uma opção de formação no referido Curso naquele momento. Assim, de um interesse inicial pela fotografia e impressão gráfica, o qual necessitou ser adiado, houve a incursão pelas linguagens artísticas, envolvendo a pintura, o desenho, a cerâmica, a modelagem, a gravura, o objeto-arte, as técnicas têxteis, além dos processos de representação gráfica e do projeto de design de interiores.

Tais vivências e experimentações, mesmo na graduação em Desenho e Plástica, já mesclaram de início conhecimentos de campos diferenciados, para além da Arte, como da Arquitetura, da Engenharia, do desenho técnico, envolvendo processos de projeto. Os conteúdos mais específicos da Arte, a modelagem, a construção tridimensional, a colagem, o desenho, a gravura, a pintura, o aprendizado de grafismos e sensibilização cromática, foram canalizados para uma produção artística que se encaminhou para o bidimensional, principalmente através do desenho. Nele, procedimentos em aquarela, nanquim e estêncil foram explorados e renderam trabalhos expostos em mostras locais e regionais e foram comercializados já enquanto estudante.

Nessas propostas, afora os processos técnicos elegidos e a elaboração manual, não mediada, os motivos apresentados variavam entre figuras humanas realistas ou estilizadas, configurando personagens fictícios, ou, em outras vezes, objetos do cotidiano, formas naturais, vegetais, enfocando também uma interpretação sintetizada, com apelo gráfico, onde palavras e/ou vocábulos estrangeiros se faziam presentes como parte da configuração visual idealizada.

Desse modo, os primeiros anos de formação artística envolveram a aproximação com um universo bastante amplo da arte, oportunizando, do ponto de vista prático, o conhecimento de materiais e especificidades das linguagens, bem como a elaboração de diferentes produções, como mosaicos, peças cerâmicas, serigrafia, litogravura e xilogravura, desenho artístico, tapeçarias, entre outros com grande ênfase à feitura manual e ao aspecto artesanal dos processos. Paralelamente a isso, devido a opção feita pela área de Arte Decorativa, havia o desenvolvimento de um processo mais racional, mais aplicado, que tinha suas bases no projeto de ambientes (que presume uma demanda externa), na visualização espacial e na representação gráfica normatizada, o qual era voltado à concepção criativa de interiores, ou seja, à arquitetura de interiores, com o planejamento de mobiliário e seleção de materiais, a distribuição de objetos em dado lugar e seu layout em conformação com parâmetros prévios. Pode-se dizer que, ao trabalhar-se com questões da expressividade artística ao lado de uma atividade de maior planejamento, como o desenho de arquitetura, a formação de graduação equacionou aspectos subjetivos e objetivos com relação ao desenvolvimento de uma poética pessoal, em um trabalho criativo autoral.

Na sequência deste percurso, uma nova graduação ${ }^{3}$, concomitante àquela já iniciada há dois anos, agregou perspectivas distintas ao confrontar procedimentos técnicos de impressão, relativos à reprodução gráfica, bem como ao adentrar ao campo da fotografia analógica e seus processos como possibilidade criativa, de registro ou reprodução da imagem. Além disso, a vivência com a necessidade de adequação de estudos, ideias e projetos a fim de que pudessem ser replicados em materiais comunicacionais impressos, possibilitou a aproximação com o trabalho de equipe, a inserção do profissional criativo em uma estrutura ou sistema preexistente que reivindica sua atividade criativa como fundamental para inserção em um mercado ou aceitação de um público-alvo.

Bastante enraizada na produção bidimensional, gráfica, essa etapa formativa permitiu o desenvolvimento de outras competências, vinculadas ao campo das artes gráficas, envolvendo o planejamento gráfico e elaboração de impressos (cartazes, folders, capas de livros, etc.), a criação de logomarcas, identidades visuais, a noção de elaboração audiovisual, a construção de embalagens, displays e painéis, entre outros. Vale lembrar que, em uma época de poucos recursos e baixa tecnologia, o modo de fazer era manual, com a arte-finalização via colagem de composições em folhas milimetradas e produção fotográfica analógica com correção manual de desacertos, entre outros. Isso impactou na produção artística pessoal, que se encaminhou para processos mais automatizados como a cópia xerográfica e inclusão de elementos impressos (jornais ou textos de impressoras matriciais).

Nesta época, a manipulação de imagens se deu no âmbito das possibilidades de repetição, de aumento/redução, de exploração do alto contraste pela reprodução de fotos em meio tom, entre outros. A colagem e montagem manual de configurações, gerando arranjos compositivos, com intervenções cromáticas de outros materiais e processos de desenho/ pintura foram largamente explorados. O aproveitamento de resíduos resultantes de experimentações pessoais (como papéis encerados do batik ${ }^{4}$ e entintados de serigrafia) foi usual. Cor e textura ganharam destaque, embora aspirando uma síntese de elementos e a exploração da relação imagem e texto, através da agregação de palavras e/ou elementos tipográficos às criações imagéticas.

A produção, neste período, voltou-se também à ilustração documental, com representação mais realista, em processos

2 - Curso de Graduação/Bacharelado em Desenho e Plástica, com opção em Arte Decorativa, iniciado em 1980 e finalizado em 1984 na UFSM.

3 - Graduação/Bacharelado em Comunicação Visual, iniciado em 1982 e finalizado em 1986 na UFSM.

4 - Processo de tingimento têxtil que utiliza a técnica de reserva com cera de abelha e parafina. 
tradicionais como grafite e nanquim, entre outros. Os elementos figurativos permaneceram em destaque.

Nesta etapa do processo formativo, aprendeu-se a olhar para fora de si, considerar a demanda externa, habituando-se a direcionar as criações a outros indivíduos. A graduação em Comunicação Visual permitiu a aproximação com tais aspectos, ao adentrar as questões de público, mercado, cliente, equipe, processos terceirizados, diferentemente da produção em arte, mais artesanal e subjetiva. Tal ponto é aqui exposto visto que se pensa ter contribuído para complementar e ampliar a visão pessoal acerca do trabalho criativo autoral, em razão de que encerra afinidades com as implicações da produção artística no contexto da Arte e Tecnologia hoje.

Abordando o assunto, com foco na dissolução de fronteiras entre a arte e os demais campos, Rush (2009, p. 190-191) destaca o importante papel de designers gráficos, colaborando na produção artística em meio computacional, afirmando: "artistas especializados em computação gráfica, especialistas em caligrafia, layout e imagens multidimensionais ajudam artistas visuais de outras áreas a se adaptar ao computador". Essa relação entre domínios diversos, com entrecruzamentos de campos, foi mais presente a partir do período das vanguardas históricas, onde também se estabeleceram novas bases para o design gráfico, desencadeando influências produtivas entre artistas e designers; por exemplo, a Bauhaus, escola de arte, design e arquitetura, sediada na Alemanha, foi um dos espaços que congregou pensamentos diversos em suas diferentes fases, propondo, em torno de seu funcionamento, a contaminação positiva entre arte, artesanato e design, entre outros aspectos.

Atualmente, é usual ocorrerem práticas no campo da Arte ou do Design nas quais os atores desloquem estes papéis, muitas vezes, designers realizando objetos artísticos ou artistas produzindo peças funcionais. Afora o apelo imagético/visual inerente ao contexto das cidades e as implicações daí decorrentes, isto também pode dar-se concomitantemente, sobretudo na época atual, em que o interesse pelo cotidiano e pelo meio urbano como fonte contínua de experiência e de atualização de novos espaços perceptivos tem direcionado muitas produções artísticas, reforçando uma aproximação arte/vida, já presente de forma significativa desde meados do século XX. Há inúmeros exemplos de artistas que adentram tais caminhos, seja de forma mais sistemática ou eventual. Vale lembrar as discussões levantadas pelas produções de Bárbara Krueger, designer e artista conceitual americana, que traz em sua obra aspectos de linguagem e símbolo, tratando de questões de gênero, poder, consumismo, as quais são naturalmente associadas a grandes outdoors, detendo um caráter gráfico bastante singular 5 .

Figura 1 - Genealogia I (detalhe e visão geral). Objeto, desenho, fotografia. 50x62cm. 1998.
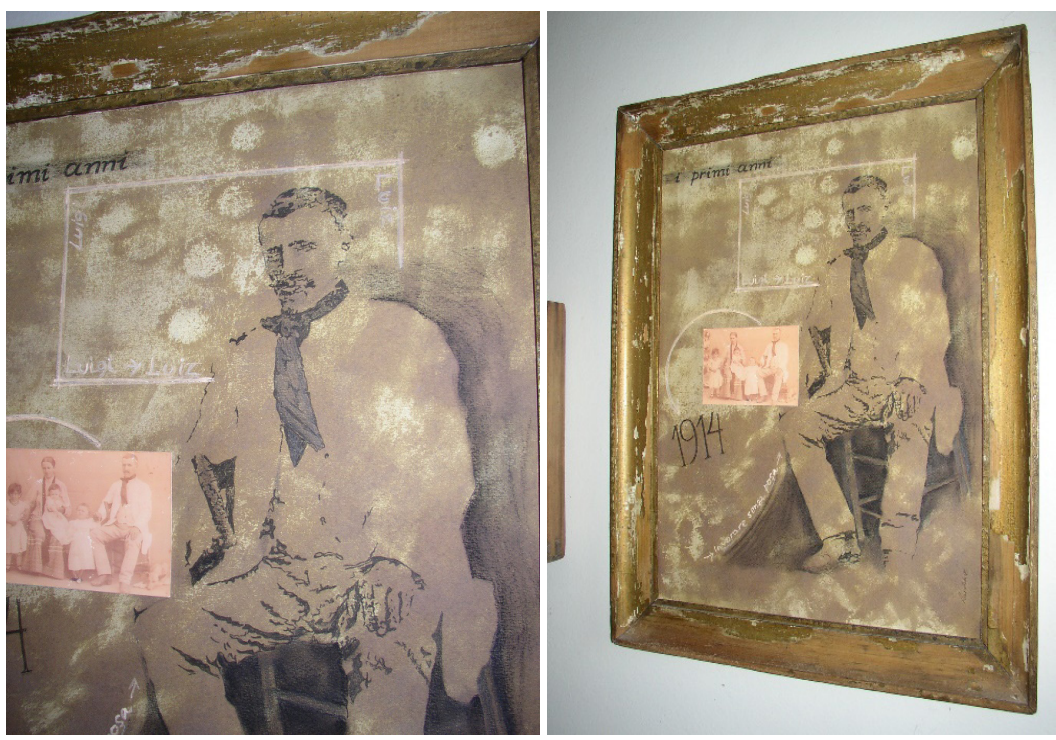

Fonte - Arquivo Pessoal

Acerca do processo pessoal, com tais bases e vivências posteriores de atuação profissional, também vinculando os campos da Arte (atuação em setor técnico/audiovisual e no ensino em instituição comunitária de ensino superior) e do Design (setor criativo em agências de publicidade e em empresas), o ingresso na UFSM como docente em 1991 lançou outros desafios referentes à produção artística. Iniciadas pelo viés do desenho, da aquarela, da colagem, e/ou da impressão têxtil, as intervenções pessoais em exposições artísticas desta época giraram em torno da figuração que permeava temas vinculados a elementos da natureza animal, vegetal e humana. Passa-se aí a reforçar uma representação estilizada, não naturalista, baseada em estilo pessoal que teve na linha um aspecto de destaque em termos de desenho.

5 Antes de ser professora na Universidade da Califórnia, entre outras instituições às quais esteve vinculada, bem como apresentar seus trabalhos em grandes mostras artísticas, Bárbara Krueger estudou fotografia e atuou como designer gráfico desenvolvendo capas para livros e revistas. Iniciando suas produções com a colagem e fotografia, a partir de 1990, volta-se para intervenções urbanas e instalações imersivas, porém permanece desenvolvendo peças gráficas. Fonte: <https://www.moma.org/artists/3266>; <http://www.theartstory.org/artist-kruger-barbara.htm>; < http://www.barbarakruger.com/>; <https://www.artsy.net/artist/barbara-kruger>. 
Em outros momentos, na sequência, há um retorno à manipulação analógica da imagem referente, utilizando processos de reconstrução da figura a partir de zonas de contraste trabalhadas com grafismo, com base na ampliação/redução de detalhes. Ao lado disso, a inserção de colagens como cópias fotográficas de reproduções de registros familiares antigos que foram resgatados e copiados em processo tradicional, feito pessoalmente em laboratório específico. Em uma destas produções, o objeto resultante envolveu moldura em madeira resgatada de pertences de familiares, evidenciando o desgaste do material e acabamento, a fim de dialogar com o tema trabalhado e construir sua visualidade (Figura 1).

Em outro caso, a ideia de caixa também aparece, mas como moldura de uma proposta artística, a qual apresenta seus elementos imagéticos em fotografia (analógica), escaneada e manipulada digitalmente. A isso é associada a impressão digital sobre papel vegetal, em um processo de colagem sobre papel artesanal (feito à mão), em camadas com recortes vazados. Nesta mesma produção, outro objeto em madeira, uma maleta antiga, resgatado de familiares, aparece associado, compondo no plano horizontal com a peça anterior exposta verticalmente na parede. As imagens em seu interior seguem a mesma linha e são recobertas por vidro transparente. A alusão é feita em função de falecimento de familiar, remetendo a um lugar vazio, uma cadeira vazia (sedia vuota), reforçada pelo termo mancanza, em italiano, que significa "falta" (Figura 2).

Figura 2 - Sedia Vuota (Peça 1/Vertical e detalhe da imagem interna). Objeto, desenho, impressão, recorte, colagem). 02 peças, Dimensões variadas. 2004
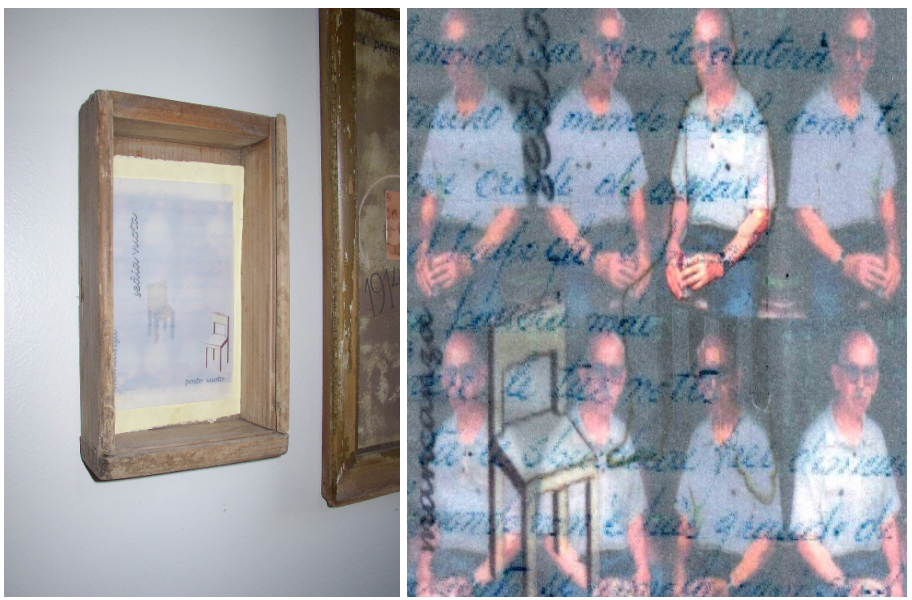

Fonte - Arquivo Pessoal

Neste período, variações em torno de tal tema e processos são realizadas, ou seja, as produções envolveram continuamente a mistura de elementos materiais físicos, bastante marcados pelo tempo, que são associados a imagens digitais (ou manipuladas digitalmente), as quais remetiam à história familiar, aos registros fotográficos antigos, aos personagens familiares e relativos a este círculo. A presença da linguagem em termos e expressões, como textos associados às imagens, torna-se uma constante, seja de forma mais sutil ou mais declarada. Os títulos das produções carregam relações com a história familiar, muitas vezes expressos nos idiomas italiano ou latim.

Desse modo, no trajeto desde a entrada no campo das Artes Visuais como expectativa profissional até o ingresso como docente na UFSM e a perspectiva de se trabalhar, neste âmbito, com a formação do artista, muito se aprendeu e muito se agregou. Os diferentes desafios, os distintos grupos de trabalho assumidos nesta trajetória, as circunstâncias pessoais, as vivências, as escolhas profissionais, tudo contribuiu de forma importante para a continuidade e amadurecimento da pesquisa artística pessoal.

\section{Incursão acadêmica: entornos de pesquisa e o coletivo}

Ao longo do percurso docente, houve oportunidade de agregar-se a grupos e coletivos artísticos locais e regionais como o Núcleo Têxtil do Rio Grande do Sul, inicialmente, e a outros, mais recentemente, como o Núcleo de Produtores Visuais de Santa Maria. Essas e outras experiências foram produtivas e enriquecedoras individualmente, contribuindo para alicerçar uma postura crítica e reflexiva face aos trabalhos artísticos desenvolvidos no percurso.

Após o doutoramento, com a aproximação mais intensa com a pós-graduação, e o envolvimento como docente e/ou na coordenação nestes Cursos $^{6}$, a demanda de criação e manutenção de um grupo de pesquisa específico surgiu face à futura

6 Atuação docente na Pós-Graduação: desde 1998 na Especialização Design de Superfície; em 2005-2006 na Especialização Arte e Visualidade; desde 2007 no Mestrado em Artes Visuais; em algumas edições desde 2012 na Especialização em Tecnologias de Informação e Comunicação aplicadas à Educação. Como Coordenadora Substituta da Especialização Arte e Visualidade em 2005-2006; na Especialização Design de Superfície desde 2008; como Coordena- 
implantação do Mestrado em Artes Visuais ${ }^{7}$ na UFSM. Nesta perspectiva, em 2005 registrou-se, junto ao CNPq (Conselho Nacional de Desenvolvimento Científico e Tecnológico), o Grupo de Pesquisa Arte e Design. Tendo em sua constituição alunos de graduação e de pós-graduação, além de pesquisadores e profissionais externos, o Grupo, além das produções teóricas, assumiu a realização de mostras artísticas sistemáticas, regulares, na cidade ou em outros locais. Com foco de investigação nos processos híbridos nas Artes Visuais e no Design, o Grupo elegeu como diretriz o entrecruzamento de campos, meios, linguagens e processos.

Neste sentido, as implicações de produção prática pessoal em mostras coletivas em conjunto com o Grupo Arte e Design constituíram sempre bons desafios e estímulos. O voltar-se à produção poética de modo mais direcionado por propósitos coletivos contribuiu para a solidificação de algumas escolhas e estratégias de trabalho já experenciadas. Por outro lado, afora o exercício contínuo e sistemático do fazer artístico vinculado a uma proposta grupal, também houve espaço para a prática curatorial, envolvendo a concepção e organização de todo tipo de apresentação expositiva em diferentes situações e locais.

Neste âmbito, surgem proposições ou temáticas emergidas do coletivo, onde a invenção, a adequação e a condução dos processos criativos individuais também se molda e se reconfigura. A atuação na linha de pesquisa Arte e Tecnologia do Mestrado em Artes Visuais igualmente impactou nas novas escolhas e procedimentos.

Assim, já em 2009, as produções avançam no campo do digital, resultando, em geral, em objetos híbridos que congregavam imagem impressa e projeções audiovisuais. Na proposta "re-ncontro", exposta na Mostra Hibri[dados], do Grupo de Pesquisa Arte e Design, a imagem impressa em vinil adesivo e fixada sobre um suporte de material transparente é justaposta a uma projeção similar que se altera continuamente em partes da figura ali apresentada, gerando movimento e transformações em sua visualidade. Trata-se de uma colagem digital de faces de dois familiares (um avô e sua neta), em temporalidades distintas (juventude do avô/passado e atualidade da neta/presente) que geram uma imagem algo ambígua e inusitada, justapondo contextos e características das referências. A ideia trabalha as questões genealógicas e seus cruzamentos, assim como as heranças psicológicas e comportamentais. A construção de outras imagens resultantes deste encontro, já ambíguo, sempre em mutação, gera outras figurações e rostos "desconhecidos". Ao partir de atributos de sujeitos distintos (olhos e bocas), propõe discutir as questões colocadas acerca de influências e aspectos familiares relativos a sensações e sentimentos, enfatizando sobretudo o olhar e expressões (Figura 3).

Figura 3 - re-ncontro (detalhe e visão geral). Objeto e projeção (impressão digital, sequência de imagens em loop). $120 \times 82 \mathrm{~cm} .2009$

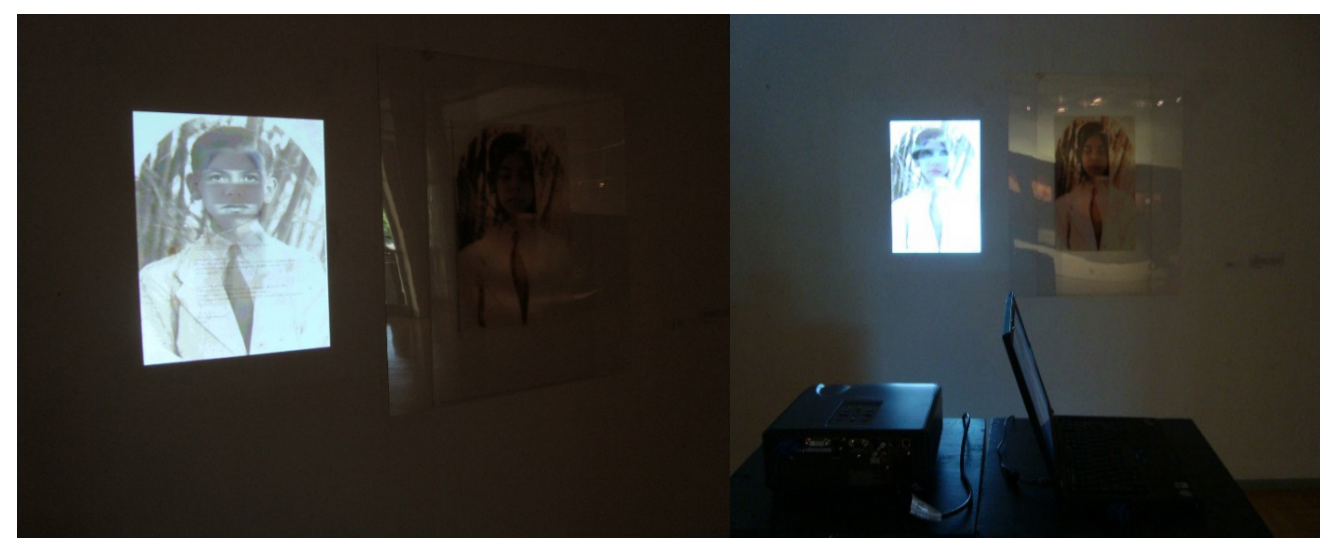

Fonte - Arquivo Pessoal

Nesta perspectiva, outras propostas foram conduzidas quando da participação em mostras de coletivos e grupos, muito embora com uma predominância de recursos impressos (sobretudo inicialmente) e não tanto audiovisuais, porém já considerando os processos híbridos em sua feitura. Em 2010, apresenta-se Crypsis, constituindo-se em um objeto formado por impressão em vinil adesivo sobre suporte acrílico, com molduras de madeira sobrepostas, o qual integrou a mostra Hibridez+1, coletiva do Grupo Arte e Design (Figura 4). O tema circundava a ideia da habilidade de um organismo em dificultar sua detecção pelos demais, explorando visualmente o conceito de mimetismo e camuflagem naturais. No que respeita as imagens referenciais (fotos antigas de familiares), agregadas a partir de repetições, misturas, justaposições, fragmentos, transparências, revelavam-se registros de memórias híbridas entre analógico e digital, à primeira vista dismórficas e dissonantes, porém capazes de gerar consonâncias ao instigar a sensorialidade do observador, em uma mistura de planos e relevos, cortes e sobreposições.

dora Substituta no Mestrado em Artes Visuais, na gestão 2015-2018.

7 Iniciado em 2007, na UFSM, do qual se participou da elaboração do projeto e todas as etapas de implantação do Curso, com orientação de alunos a partir de 2008. 
Figura 4 - Crypsis (Vista frontal e detalhe). Objeto (policarbonato transparente, vinil adesivo, madeira). 160x100cm. 2010

Fonte - Arquivo Pessoal
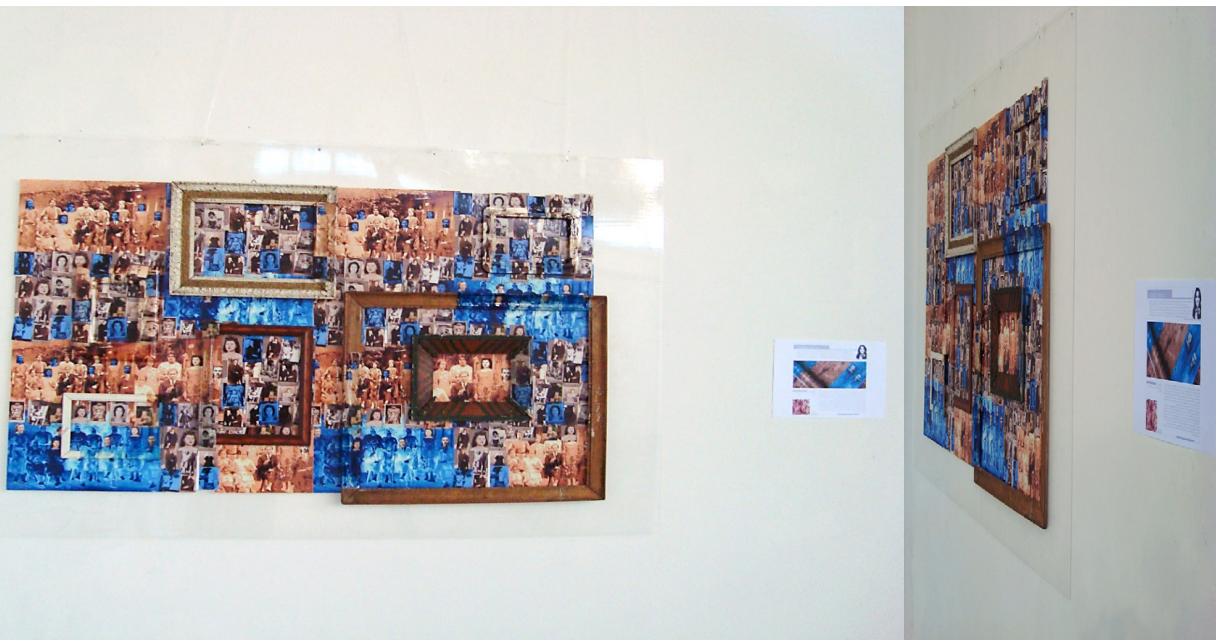

Outro exemplo é a produção "Sette Chiavi", realizada em 2012, para a mostra coletiva "Secreto" do Núcleo de Produtores Visuais de Santa Maria (Figura 5). Nela, dois objetos, um vertical, exposto na parede e um horizontal, sobre um suporte, dialogavam acerca do tema, voltado novamente às memórias familiares, trazendo trechos de antigas cartas e poemas (entre os anos 40-50, trocados entre os pais quando noivos) e um audiovisual com imagens e sons relacionados ao contexto. Os materiais selecionados incluíram o uso de base transparente, apresentando um conjunto de envelopes em acetato que tinha em seu interior os escritos e imagens dos sujeitos envolvidos na narrativa.

A predominância cromática sépia remetia à passagem do tempo e oxidação dos registros guardados. Junto a tais objetos planos, em papel impresso e acetato, sete diferentes chaves antigas, amarradas com finos fios de costura conectavam as mensagens nos envelopes. Paralelamente, em suporte horizontal, uma maleta antiga de madeira, entreaberta, continha em seu interior, o loop de um vídeo curto, que apresentava um passeio visual por objetos antigos familiares, onde a luz em movimento acrescentava um tom de mistério e ênfase ao arranjo. $O$ áudio, composto por vozes, falas e sons indistintos, remetia a conversas e, potencialmente, segredos trocados.

Figura 5 - Sette Chiavi. Objeto (acrílico, peças em madeira e metal, dispositivo para audiovisual). 02 peças. Dimensões variadas. 2012

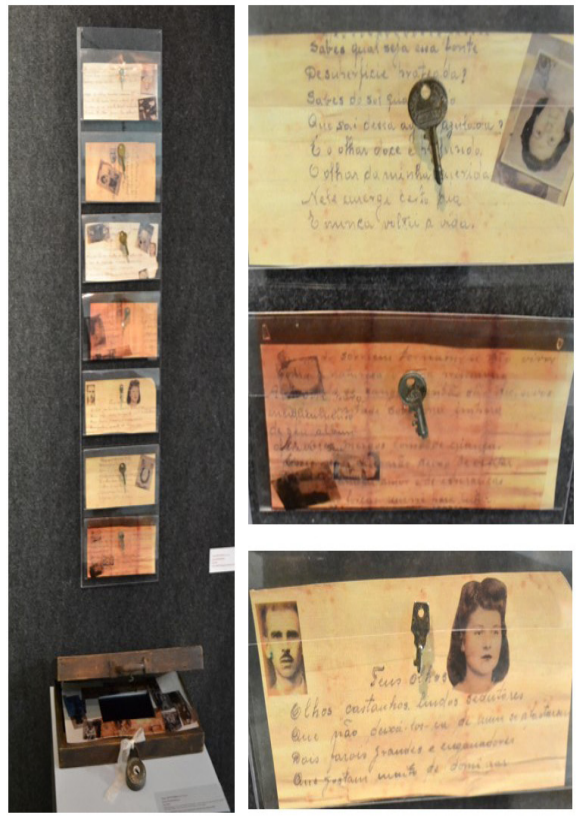


Pensar a produção em Arte e Tecnologia implica considerar as potencialidades de hibridismos e mestiçagens nas manifestações artísticas. Bausbam (2007) coloca que a arte hoje precisa ser compreendida em sua natureza híbrida como campo de entrecruzamento de diversas determinações, inexistindo possibilidade de uma pureza visual; seus dispositivos são complexos, maleáveis, instáveis, em transformação. Por sua vez, André Parente (2005), situando o new media como uma criação artística onde convergem as artes plásticas, o audiovisual e a arte eletrônica interativa, ressalta o fato de acarretar em questionamentos acerca do conceito de objeto da arte ou mesmo a repensar os objetos artísticos como dispositivos, "a meio caminho entre dimensões técnicas e estéticas, subjetivas e discursivas" (PARENTE, 2005, In: DOMINGUES; VENTURELLI, 2005, p. 19).

Michael Rush (2006), referindo-se à instalação e incremento da arte digital, tendo em vista um ambiente cultural centrado na tecnologia computacional, recorda a afirmação de Peter Weibel: "a imagem é um sistema dinâmico", remetendo ao universo fluído, sempre mutável, potencialmente interativo inerente ao computador (RUSH, 2006, p. 164-165). Relativamente à adesão a estes novos meios, o autor lembra que certa resistência inicial de artistas de destaque foi sentida, e, em geral, os profissionais ligados a institutos de pesquisas foram os primeiros a propor produções neste campo, as quais geralmente resultavam de trabalhos em equipe com engenheiros, informatas, cineastas, designers, compositores/músicos, entre outros.

Tais colocações demarcam mesmo inicialmente algumas problemáticas inerentes à produção em Arte e Tecnologia, as quais atentam para novas posturas dos artistas neste contexto, onde as equipes e a autoria compartilhada são algumas delas. Assim, envolver-se em uma produção coletiva, de autoria múltipla, é uma possibilidade e que fortalece grupos e equipes, não desmerecendo o curso da investigação artística pessoal. Neste sentido, houve oportunidade de compartiIhar algumas propostas com integrantes do Grupo Arte e Design, como exemplo, em 2013, a proposta coletiva Paisagens Cambiantes, apresentada em Portugal na mostra 'Nada a Fazer?', em Viseu, ou em 2017, a produção 'PluralDesigual', uma proposta interativa de realidade aumentada, realizada com dez integrantes do Grupo Arte e Design no Festival de Projetos Interativos no Evento Design+2017 na UFSM. Além das citadas, outras incluíram a participação de parceiros de equipe, construindo a visualidade da proposta, como em 'DezxDez Ampliado', em 2015, na Mostra 'DEZ', exposição coletiva do Grupo Arte e Design/Ano 10, na Sala de Exposições Cláudio Carriconde na UFSM.

Dessa forma, as produções têm sido conduzidas ao redor de questões individuais de pesquisa e de propósitos grupais. Desde 2007, diferentes projetos de pesquisa e extensão ${ }^{8}$ foram instigadores e provocadores da produção textual reflexiva e tiveram seus efeitos na prática artística. A partir de tais projetos, as demandas práticas surgiram e foram construídas, gerando, em seu entorno, escritos e desdobramentos em ações e eventos na área.

\section{Atravessamentos da poética: status da produção em processo}

As recentes produções, após 2016, apresentam-se em uma linha coerente com o percurso. Mudanças imagéticas sutis revisitam as referências pessoais, vinculando-as a outros aspectos, que envolvem preocupações latentes como artista e designer, como a questão dos recursos naturais e da ação humana sobre a natureza'. Assim, algumas destas propostas associam o tema da herança e genealogia (árvore genealógica) à natureza, mais especificamente, a imagens de uma vegetação, com destaque para o entrelaçamento de galhos e sua força visual, bem como a parte verde da planta, que sofreu a ação de um componente ambiental, praga ou ação externa, danificando sua folhagem. Às imagens da planta, captadas por dispositivo móvel, são agregadas outras, de origem analógica, já numerizadas (COUCHOT, 2003) e manipuladas digitalmente, com edição cromática e formal, as quais revelam registros fotográficos antigos de familiares. Por vezes, sobre essas imagens resultantes, impressas em papel fotográfico, são adicionadas impressões em carimbo, contendo informações textuais e/ou formas do alfabeto e ornamentações gráficas, enfatizando ou complementando o conjunto. O modo de finalização das peças e sua apresentação nas mostras levam em conta as condições e características dos espaços expositivos.

Um exemplo é a produção Green-Brown, exposta na Mostra DezFORMAS, do Grupo Arte e Design, em 2017, no Museu de Arte de Santa Maria (MASM), a qual articula particularmente tais questões, explorando contrastes cromáticos, bem como a visualidade do encontro entre as imagens de referências familiares e as imagens das formais naturais, que são contrapostas em áreas de verde e marrom (green-brown), remetendo ao florescimento e amadurecimento/declínio da planta. Associa-se a isso a agregação de um texto, o qual é carimbado sobre as imagens, remetendo às impressões e marcas recebidas geneticamente de antepassados (Figura 6). As formas verbais da linguagem escrita são indicativas do âmbito em que se constrói a proposta.

\footnotetext{
8 "Hibridações entre Arte e Design: configurando Novas Possibilidades na Produção Artística", "Manifestações Artísticas Híbridas"; "Superfícies Contemporâneas: Percursos entre Arte e Design".

9 Desde 1989, com maior ênfase, natureza e ecologia tem sido tema de pesquisa, sob o aspecto teórico-conceitual e visual, destacando as relações entre recursos naturais e cultura humana.
} 
Figura 6 - Green-Brown (detalhes). Objeto (impressão em papel, carimbo, vinil adesivo). Dimensões variadas. 2017

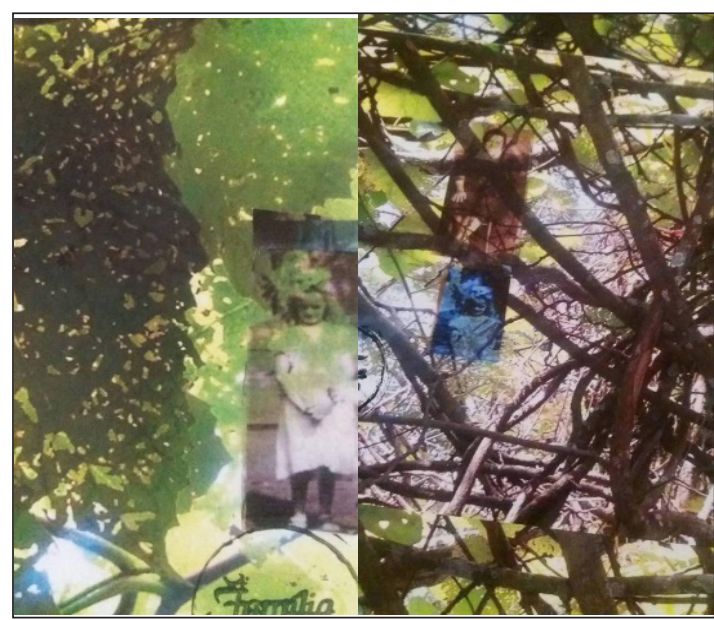

Fonte - Arquivo Pessoal

Por sua vez a produção Heredium, de 2017, exposta na Mostra "Arte+Pesquisa", coletiva dos professores do Mestrado em Artes Visuais da UFSM, era constituída de um objeto híbrido, composto, por um lado, de uma projeção de imagens (palavras) em formato de "8", com termos em latim que remetiam ao contexto do trabalho e, por outro lado, de uma peça plana em base acrílica com imagens em impressão digital, as quais recebiam a projeção em seu entorno. Conforme texto divulgado no evento:

A proposta remete a um tema de interesse pessoal, presente em produções artísticas desde o final da década de 90 , no qual questões da passagem do tempo, da memória e da afetividade vinculadas aos registros e reminiscências familiares são instigadores e alavancadores da produção artística, feita associando diferentes meios. Heredium (do latim, herança), reúne imagens digitais inseridas em objetos de material translúcido e transparente, em cujas laterais movimentam-se conceitos disparados e animados de diferentes formas, visualizados em uma projeção vertical. $\mathrm{O}$ conjunto, em sua visualidade, destaca a conotação com as diafaneidades do existir, em seus tempos e fases distintos, onde nem tudo se vê, embora muito se olhe e pouco se saiba em termos de origens e heranças. Considerando a ascendência biológica natural dos seres vivos - humana e vegetal, neste caso - recorda que os parentescos nem sempre são imperativos, podendo ser somente indicativos (MINUZZI, 2017, s/p).

Similarmente às anteriores, a proposta "geneRalogias" 2017, na Mostra PluralSingular, do Grupo Arte e Design, abordou as questões de herança familiar através de imagens (fotografias antigas e vegetação) associadas a texto e repetição de elementos. A cada imagem é associada uma letra, como em uma catalogação ou ordem estabelecida (veja-se o herodograma ${ }^{10}$ ), evidenciando a sequencialidade do tema e suas implicações temporais no transcorrer de gerações (Figura 7).

Figura 7 - geneRalogias (detalhe). Objeto (suporte acrílico, impressão digital, colagem). 14 peças, Dimensões variadas. 2017

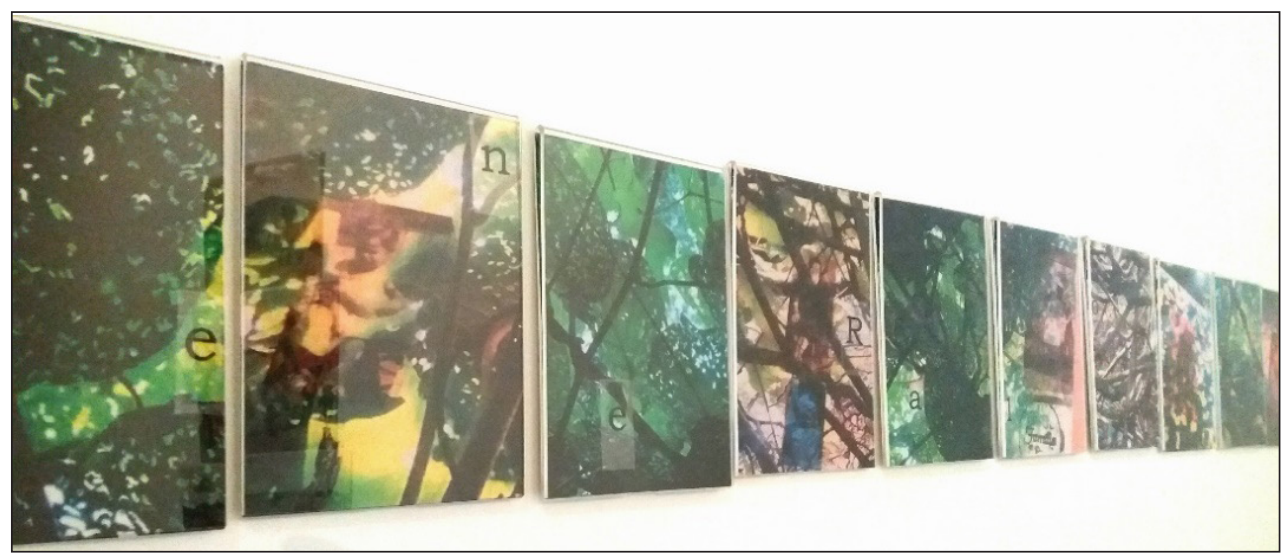

Fonte - Arquivo Pessoal

10 - Similar a uma árvore genealógica, constitui-se de um diagrama usado para descrever a história familiar em termos de ascendência, descendência e incidência de determinada característica. 
Outras experiências suscitaram proposições bem distintas, como a mostra Fronteras-Fronteiras, do projeto Referências Cruzadas, do qual se participou em 2017, sendo que envolveu trinta artistas de quatro países (Brasil, Argentina, Uruguai, México), com mostras na Argentina e Brasil, inicialmente. Com um sentido mais instigador, apresenta-se uma produção realizada em xerox e intervenção pictórica/gráfica manual, totalmente despretensiosa de um fazer elaborado ou know-how técnico e artístico. A produção enfatiza a gestualidade, o inacabado e o uso do material não-nobre, inespecífico e popular para dialogar com as questões conceituais que emergem do tema Fronteiras. O uso do texto como imagem e sua repetição, gerando elementos compositivos e formais, distintos e recombináveis, é enfatizado com a exploração de contrastes cromáticos entre o preto do texto, o branco do fundo, e o vermelho e o marrom dos contornos (Figura 8).

Vale lembrar que a cópia xerográfica foi usual em manifestações artísticas, considerando os direcionamentos surgidos a partir da Arte Postal nos anos 60, que explorava o uso de tecnologias de reprodução, questionando os meios de comunicação de massa e o próprio sistema da Arte, vindo também a constituir um tipo de antecedente das experiências colaborativas via Internet, comuns hoje. Igualmente, neste período, a produção dos artistas era artesanal, bem como muitos exploravam o texto como visualidade, geralmente em contextos de abordagem social e política, já que tinha como mote uma democratização das mensagens (NUNES, 2010). Pessoalmente, o xerox foi utilizado em diversas produções entre os anos 1982 a 1986, em experimentações com o desenho artístico, por vezes associado a textos (tipo formulários) de impressoras matriciais. Algumas das produções resultantes participaram de mostras em Porto Alegre e Santa Maria.

Figura 8 - Delimite-se. Objeto modulável (xerox, recorte, pintura). Dimensões variadas. 2017
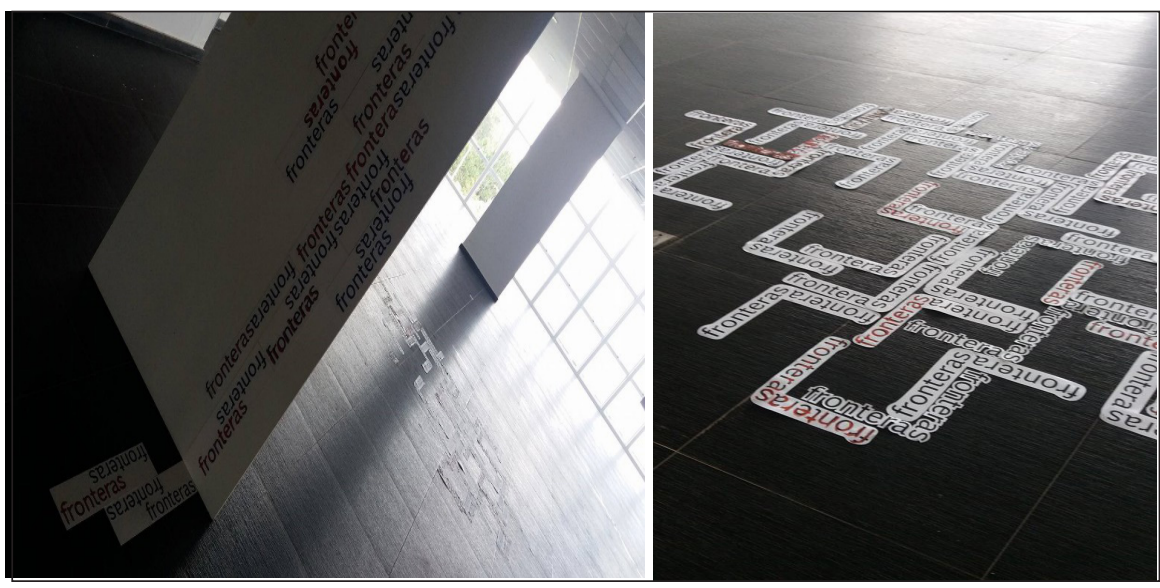

Fonte - Arquivo Pessoal

No tocante a tais processos, abordando questões implicadas na arte atual, a partir das modificações decorrentes da era da informação e impostas pela Internet no pensamento e comportamento humanos, Nicolas Bourriaud (2009) destaca o fato das manifestações não se caracterizarem por produtos acabados, expostos para serem contemplados. Ao contrário, lembra que a arte contemporânea torna-se muito mais "um local de manobras, um portal, um gerador de atividades", onde "bricolam-se os produtos, navega-se em redes de signos" (BOURRIAUD, 2009, p. 16). Para o autor, isto acarreta em uma nova configuração da relação entre quem propõe e quem frui (onde os conceitos de originalidade e criação se dissipam), além de legitimar e ratificar uma cultura do uso, configurada na pós-produção. Para tal, o autor considera a obra de arte como um término provisório de uma "rede de elementos interconectados", servindo como "enredo múltiplo", "na cadeia infinita das contribuições" (BOURRIAUD, 2009, p. 16-17). Ressalta, ainda, que a obra se torna um agente ativo, em contraposição a objetos de uma cultura passiva, já que esta nova forma cultural pressupõe uma colaboração negociada entre artista e espectadores na construção do sentido, os quais operam colocando em funcionamento formas e estruturas preexistentes na esfera sociocultural.

Castillo (2008, p. 314) reforça o caráter processual da arte atual, referindo que "vem jogando com o efêmero", com interesse na "transitoriedade dos materiais e meios". Enfocando as questões relativas à apresentação das propostas artísticas e seus espaços, a autora coloca que as exposições ampliam o campo de atuação do artista, potencializando suas possibilidades expressivas e adquirindo, assim, "a lógica de projeto artístico" (CASTILLO, 2008, p. 315).

Um exemplo estimado pessoalmente no campo artístico é o trabalho conduzido já há algum tempo por Mônica Nador, artista paulistana (pintora, desenhista, gravadora), que, entre outras realizações, integrou-se à comunidade do Jardim Miriam (criando o JAMARC/Jardim Miriam Arte Clube) e lá desenvolveu uma proposta colaborativa com a comunidade, de autoria compartilhada e transformadora do ponto de vista social e humano ${ }^{11}$ Singularmente, os resultados ganham proximidade

11 - Fonte: <http://jamac.org.br/>; <http://enciclopedia.itaucultural.org.br/pessoa8539/m\%C3\%B4nica-nador>. 
com a estamparia e o projeto de padrões têxteis e/ou de superfície, com foco no estêncil, aplicados a grandes murais, fachadas e utilitários têxteis (NADOR, 2012). Tais produtos produzem deslocamentos conceituais e práticos, borrando as fronteiras entre peças artísticas ou de uso, arte ou design.

\section{Considerações Finais}

Afora uma reflexão envolvendo a produção artística individual, que resgata passos do percurso, permanece o desejo de adentrar mais profundamente às perspectivas e desdobramentos do trabalho, avançando onde parece se tocar somente a superfície. Isso pode se dar percorrendo experiências e posturas pessoais, para extrair daí seus produtos mais relevantes. O desafio de ser professora-artista e assumir tal tarefa ao lado das tantas e diversas solicitações acadêmicas, por um lado limita o alargamento de um trajeto individual de pesquisa artística, por outro retém, de forma positiva, as experiências partilhadas na formação discente em um campo único e instigante sob vários aspectos, que vão muito além de estabelecer uma obra pessoal enquanto artista visual, ou seja, conectam saberes, percepções, formas de ver, colocando em contato sensibilidades e vivências únicas, em momentos de cada um dos envolvidos.

Certamente, há necessidade constante de articulação e adensamento de questões teórico-conceituais e estéticas na produção pessoal. Fica o desejo de encontrar brechas e vieses em meio ao estreito espaço de fomento à própria produção, que se acha mesclada, quase amalgamada, às horas-aula, às orientações, às tarefas administrativas, às tantas reuniões e compromissos acadêmicos. O tempo da pesquisa e o tempo da criação necessitam de janelas abertas e conduções inéditas. Explorar outras vertentes, desvendar vetores do próprio trabalho no(s) campo(s) elegido(s) e alcançar a proximidade das manifestações artísticas coerentes a si, propulsoras de outras percepções e sentidos, inovadoras em seu âmago, ou seja, fazer Arte, sempre, sob qualquer pretexto, sendo plural e singular concomitantemente.

\section{Referências}

BASBAUM, R. Além da pureza visual. Porto Alegre: Zouk, 2007.

BOURRIAUD, N. Pós-produção: como a arte reprograma o mundo contemporâneo. São Paulo: Martins, 2009.

CASTILLO, S. S. del. Cenário da arquitetura na arte: montagens e espaços de exposições. São Paulo: Martins, 2008.

MINUZZI, R. F. B. [Texto sobre a produção artística]. In: Mostra Arte+Pesquisa PPGART 10 anos. Santa Maria: PPGARTUFSM, 2017.

NADOR, M. Mônica Nador. Catálogo. Textos Thaís Rivetti. São Paulo: Pinacoteca do Estado, 2012.

NUNES, F. O. Crtl+Alt+Del: distúrbios em arte e tecnologia. São Paulo: Perspectiva, 2010.

PARENTE, A. As virtualidades da imagem panorâmica. In: DOMINGUES, D.; VENTURELLI, S. (org.) Criação e poéticas digitais. Caxias do Sul, RS: EDUCS, 2005. p. 19-26.

RUSH, M. Novas mídias na arte contemporânea. São Paulo: Martins Fontes, 2006. 